\section{"FACULTAD DISCRECIONAL", PLANEACIÓN Y EFICIENCIA EN LA GESTIÓN DEL RECURSO HUMANO MILITAR*}

\author{
Javier G Rincón Salcedo** \\ Universidad Militar Nueva Granada \\ Edna M Morales Vargas ${ }^{* * *}$ \\ Universidad Militar Nueva Granada
}

Fecha de recepción: 5 de octubre de 2009

Fecha de aceptación: 16 de noviembre de 2009

\section{Resumen}

El ejercicio de la Facultad Discrecional como mecanismo legal otorgado al ejecutivo para que pueda retirar por "Razones del Servicio" a funcionarios Militares, ha sido objeto de importantes delimitaciones por parte de los jueces administrativos y constitucionales. Estas delimitaciones, lejos de constituir barreras para el ejercicio de la actividad de la administración dentro de un país en conflicto, deben ser consideradas, por una parte, como mecanismos que, por

* $\quad$ El presente artículo de reflexión, se inscribe dentro del Proyecto de Investigación sobre "Estabilidad Laboral en las Fuerzas Militares" que se desarrolla al interior del Grupo de Derecho Público de la Facultad de Derecho de la Universidad Militar Nueva Granada de Bogotá y constituye una continuación de la investigación desarrollada por uno de los autores (Dr. Javier Rincón Salcedo) en el seno del CESEDEN, España.

** Abogado de la Pontificia Universidad Javeriana, Magíster en Derecho público Fundamental y Doctor en Derecho de la Universidad de Poitiers, Francia. Profesor - investigador Grupo de Investigación en Derecho Público de la Facultad de Derecho de la Universidad Militar Nueva Granada, Bogotá. Áreas principales de investigación: Derecho Público Militar, Globalización Jurídica; Función pública, Contratación Publica. javier.rincon@unimilitar.edu.co

*** Abogada Universidad Militar Nueva Granada. Estudiante Especialización en derecho comercial y contractual de la Universidad del Rosario. Jóven Investigadora. Grupo de Investigación en Derecho Público de la Facultad de Derecho de la Universidad Militar Nueva Granada, Bogotá. Áreas principales de investigación: Derecho Público Militar, Responsabilidad Civil, Derecho Constitucional.milena.morales@. unimilitar.edu.co la vía de considerar que las Actas de evaluación son parte del Acto Administrativo de Retiro, permiten garantizar el Derecho de Defensa de los funcionarios militares, y por otra parte, como instrumentos que contribuyen a "administrar mejor", en la medida que ejercen una presión sobre la Administración para que esta implemente una política coherente de Recursos humanos, que, naturalmente, redundará en el desarrollo de una gestión más eficiente del Estado.

\section{Palabras Clave}

Facultad Discrecional, motivación, motivos, eficiencia, gestión, recursos humanos, derecho de defensa, funcionarios militares, Fuerzas Militares.

\section{"DISCRETION", PLANNING AND EFFICIENCY IN MILITARY HUMAN RESOURCE MANAGEMENT}

\begin{abstract}
The exercise of the discretion granted as a legal mechanism to enable the executive to withdraw for "Reasons of Service" Military officials, has been subject to important constraints on the part of administrative and constitutional courts. The divisions, far from constituting barriers to the exercise of administrative activity within a country in conflict, should be considered, on the one hand, as mechanisms which, by way of considering that the assessment records are part of the Administrative Act Retirement, to guarantee the right of defense of military officials, and on the other hand, as instruments contributing to "better manage", to the extent that exert pressure on the Administration to implement a coherent policy that Human Resources, which, of course, will result in the development of more efficient management of the state.
\end{abstract}

\section{Key Words}

Discretionary power, motivation, moving, efficiency, management, human resources, right to defense, military officials, Armed Forces 


\section{INTRODUCCIÓN}

Coinciden en afirmar los diferentes autores ${ }^{1}$ que defienden la globalización jurídica, que el actuar de toda administración pública en el mundo contemporáneo, debe estar determinado por la búsqueda de la materialización del principio de eficiencia en su proceder. Es decir, debe ser un actuar en el que el aprovechamiento de los recursos sea optimizado de modo tal, que con los mismos pueda beneficiar de manera real a los ciudadanos, tanto en sentido particular, es decir en cuanto individuos, como también en sentido general, es decir como colectividad ${ }^{2}$.

Dentro de este contexto global y teniendo en cuenta, por una parte, la situación social, política y económica colombiana y por otra parte, que la administración pública es la garante de la aplicación de los mecanismos necesarios para el desarrollo de una actividad eficiente del Estado, considero que resulta de especial interés, desde el punto de vista jurídico-económico, en aras de realizar un análisis que aporte elementos concretos al estudio de la planeación de recursos humanos dentro

Ver, por ejemplo, ABATE, Bernard, La Nouvelle Gestion Publique, LGDJ, París, 2000; AUBY, Jean-Bernard, La globalisation, le droit et l'Etat, Montchrestien, Paris, 2003; JAMES, Harold, From Grandmotherliness to gouvernance. The evolution of IMF conditionality, Finance and Developpement Review, Vol 35, N4, 1998, p.44.

2 En este sentido resulta oportuno precisar que la Constitución Política de 1991 incorpora el concepto de eficiencia que en términos económicos consiste en la utilización óptima de los recursos disponibles y que aplicado a la gestión estatal, en los términos de la Corte Constitucional colombiana significa, "la adecuada gestión de los asuntos objeto de ella partiendo del supuesto de los recursos financieros -casi siempre limitados- de los que dispone la hacienda pública. En otros términos, el Estado, por razones de interés general, está obligado a efectuar una adecuada planeación del gasto de modo tal que se oriente con certeza a la satisfacción de las necesidades prioritarias para la comunidad sin despilfarro ni erogaciones innecesarias". Sentencia C-479 del 13 de agosto de 1992 (Ms.Ps.: Drs. José Gregorio Hernández Galindo y Alejandro Martínez Caballero). de la Administración Pública, el proponer una reflexión que teniendo como línea directriz la actividad eficiente del Estado, entendida esta eficiencia en términos económicos ${ }^{3}$, permita determinar el impacto que puede y tiene el ejercicio de la facultad discrecional por parte de la Administración Pública frente a los funcionarios públicos al servicio de las Fuerzas Militares sobre la garantía de los Derechos individuales y los intereses de la colectividad.

Para trabajar esta temática general quisiera desarrollar el caso especifico del Estado Colombiano, dado que, aunado a la situación política particular en la que se enmarcan las actividades de las Fuerzas Militares colombianas ${ }^{4}$, este Estado ha sido recientemente condenado, con fundamento en la indebida utilización de la Facultad Discrecional que le otorgó la ley $^{5}$ a

3 "Eficiencia: Ausencia de despilfarro o utilización de los recursos económicos que reporta el máximo nivel de satisfacción posible con los factores y tecnología dados" SAMUELSON/NORDHAUS, Economía, Décimo sexta edición, McGraw-Hill, p.726.

4 Colombia es un país que afronta un conflicto interno desde hace más de 40 años, que ha llevado a que hoy, sus Fuerzas Militares sean el mayor empleador del país y el gasto militar uno de los rubros más importantes dentro del presupuesto nacional, lo que hace que el estamento armado sea un excelente campo de análisis, por una parte, de la relación existente entre la discrecionalidad de la Administración, los límites del acto administrativo y la eficiencia en el actuar del Estado y por otra parte, de la relación existente entre el ejercicio de la discrecionalidad y el control jurisdiccional y ciudadano de la actividad de la administración pública.

5 Decreto 1428 de 2007 Art. 104. "RETIRO DISCRECIONAL. Por razones del servicio y en forma discrecional, se podrá disponer el retiro de Oficiales y Suboficiales, con cualquier tiempo de servicio, previa recomendación del Comité de evaluación para el efecto, el cual estará conformado por el segundo comandante de fuerza, el inspector general, el Jefe de personal de la respectiva fuerza, y el comandante de la unidad operativa a la cual pertenezca. Cuando se trate de oficiales se requiere previo concepto de la Junta Asesora del Ministerio de Defensa para las Fuerzas Militares. El acto administrativo de retiro se regirá por lo dispuesto en el articulo 99 de este 
la administración para desvincular "por razones del servicio" a sus funcionarios militares, a indemnizar y reintegrar al servicio activo a efectivos retirados por esta vía ${ }^{6}$ o a reformular actuaciones administrativas, como mecanismo para la protección de derechos individuales. Esto, no solo ha significado un detrimento del patrimonio del Estado, sino que además ha permitido "constatar" que se están excluyendo efectivos cuyas calidades militares eran incuestionables; y en cuya preparación y formación el Estado había invertido sumas muy importantes de dinero, lo que pone en duda la planeación eficiente de Recursos humanos al interior de las Fuerzas Militares. Lo anterior, por cuanto desde el punto de vista de la racionalidad que debe dirigir la actividad de todo agente económico, resulta por lo menos difícil explicar, por qué si el Estado ha invertido importantes sumas de dinero en la preparación de alguno de sus efectivos, intempestivamente, fundamentado únicamente "en unas razones del Servicio", lo desvincula

Decreto". Decreto 1428 de 2007 Art.99 "RETIRO. Retiro de las Fuerzas Militares es la situación el la que los oficiales y suboficiales, sin perder su grado militar, por disposición de autoridad competente, cesan en la obligación de prestar servicios en actividad. El retiro de los oficiales en los grados de oficiales generales o de insignia, Coronel o Capitán de Navío se hará por Decreto del Gobierno; y para los demás grados incluyendo los suboficiales, por resolución ministerial, facultad que podrá delegarse en el Comandante General o Comandantes de Fuerza.

Los retiros de oficiales deberán someterse al concepto previo de la Junta Asesora del Ministerio de Defensa para las Fuerzas Militares, excepto cuando se trate oficiales Generales o de Insignia, e inasistencia al servicio sin justa causa justificada, de acuerdo con lo previsto en el Código Penal Militar para el delito de abandono del servicio. (...)"

6 Ver por ejemplo, Consejo de Estado - Sala de lo Contencioso Administrativo - Sección Segunda - Subsección A, Sentencia 25000-23-25-000-200007584-01(2903-03) de 30 de noviembre de 2006 MP Jaime Moreno García; Consejo de Estado - Sala de lo Contencioso Administrativo - Sección Segunda - Subsección B Sentencia 250002325000199230152 01. (4743 - 2003) de 2 de octubre de 2008 MP Jesús María Lemos. de la Institución, perdiendo así la posibilidad de recuperar su inversión ${ }^{7}$.

A pesar de que como lo acabamos de mencionar, los recientes fallos de los tribunales dejan en evidencia un desfase entre la utilización de la Facultad discrecional y la obligación de ejercer de manera efectiva una actividad administrativa eficaz, acorde con los principios del Estado moderno globalizado, los mismos han sido objeto de fuertes críticas por parte del estamento militar, por cuanto se ha considerado que estas decisiones judiciales han impuesto unos límites al ejercicio de la Facultad discrecional, que van en contra de la operatividad de unas Fuerzas Militares cuya actividad se desenvuelve en un país en conflicto. Sin embargo, tomando una posición opuesta a la manifestada por los críticos de estas decisiones y fundamentado en un análisis jurídico-económico, en el presente escrito buscaré demostrar que los límites que por vía jurisprudencial se le han impuesto al ejercicio de la facultad discrecional para desvincular funcionarios militares de las fuerzas Militares, no son "nocivos" para la operatividad de la institución y por el contrario "contribuyen a administrar mejor" 8 . Esta afirmación se sustenta en el hecho que las limitaciones impuestas por los jueces, crean las condiciones para que por la vía de la adecuación de la exigencia de motivación suficiente al ejercicio de la facultad discrecional como presupuesto esencial para el

$7 \quad$ Es pertinente precisar que la perspectiva económica que se propone para el presente análisis, es una opción académica que no pretende conocer la importancia del estudio de la Facultad Discrecional para desvincular funcionarios militares, a partir de otros principios constitucionales como los consagrados en los artículos 122, 201 y 216 y s.s. Lo que este análisis busca, es ofrecer una reflexión que contribuya a la evaluación del ejercicio de la facultad discrecional desde la perspectiva de la utilización de los recursos públicos, desbordando la simple perspectiva de poder de la administración.

8 En este sentido ver, FERNÁNDEZ, Tomás-Ramón, Discrecionalidad Arbitrariedad y Control Jurisdiccional, Palestra Editores, 2006, p.358-365. 
ejercicio efectivo del derecho de defensa (I), no solo se garanticen adecuadamente los derechos de los individuos, sino que se genere para la administración, una correlativa presión para que implemente una planeación coherente de la utilización de sus Recursos Humanos; la cual, determinada por la consolidación de un control efectivo por parte de la colectividad, redundará, de manera natural, en beneficio de un aprovechamiento más eficiente de los recursos económicos que les son entregados a estas instituciones (II).

\section{LA MOTIVACIÓN SUFICIENTE, UNA GARANTÍA DEL EJERCICIO DEL DERECHO DE DEFENSA}

En sentencias recientes de tutela, sin entrar a cuestionar la existencia misma de la facultad discrecional del Estado para desvincular a los funcionarios de las Fuerzas Militares por "razones del servicio", ni mucho menos entrar a cuestionar la existencia de la discrecionalidad administrativa, tanto el Consejo de Estado ${ }^{10}$

9 Ver las sentencias C-525 de 1995 M.P. Vladimiro Naranjo Mesa, C-368 de 1999 M.P. Eduardo Cifuentes Muñoz, C-942 de 2003 M.P. Alfredo Beltrán Sierra, C-1173 de 2005 MP Manuel José Cepeda y C-179 de 2006 M.P. Alfredo Beltrán Sierra. En estas sentencias la Corte Constitucional confirma la constitucionalidad del Retiro Discrecional.

10 Sentencia: 05001-23-15-000-2009-00203-01 Magistrado Ponente: Susana Buitrago Valencia. Fecha: 28 de mayo de 2009- Consejo de Estado - Sala de lo Contencioso Administrativo - Sección Quinta (Acción de Tutela). El caso que analiza el Consejo de Estado en sede de Tutela, el accionante era un capitán que fue retirado del Ejército Nacional en forma discrecional por razones del servicio. El oficial siempre estuvo en la lista uno del ejército (la mejor calificada) y no tenía investigaciones en su contra. En consecuencia, en su acción el accionante indica que la Nación vulneró sus derechos al debido proceso y al trabajo en la medida en que nunca existió recomendación del comité correspondiente y si ese comité llegó a existir, le vulneraron el derecho a la defensa porque nunca le dijeron qué determinación o decisión había tomado. como la Corte Constitucional ${ }^{11}$ confirman que si bien el acto administrativo de retiro de un funcionario militar, fundamentado en la Facultad Discrecional que le otorgó la Ley a la Administración ${ }^{12}$, no debe motivarse exhaustivamente, sí debe estar amparado en razones objetivas y razonables, y sostienen, en aras de garantizar el Derecho al Debido Proceso y el Derecho de Defensa de los tutelantes, que esas razones objetivas deben estar consagradas en los informes que tienen la obligación de expedir los comités o juntas encargadas de emitir las recomendaciones en que se sustentaron las decisiones. Informes que deben ser comunicados al afectado junto con el Acto Administrativo de desvinculación. En otros términos, consideran los jueces de tutela que "las razones del servicio" no constituyen una motivación suficiente del acto administrativo si el mismo no esta acompañado por unos informes que de manera clara y objetiva expliquen cuales son los motivos determinantes de la expedición del Acto Administrativo ${ }^{13}$ y una tal insuficiencia,

11 Corte Constitucional. T-111 de 20 de febrero 2009, M.P. Clara Elena Reales.

12 Decreto 1428 de 2007 Art.99 y 104.

13 Corte Constitucional, Sentencia C-734 de 2000, M.P. Vladimiro Naranjo Mesa "la discrecionalidad con la que puede contar la administración en determinados eventos no puede confundirse de manera alguna con arbitrariedad, ya que dicha discrecionalidad no es absoluta, sino que se circunscribe a unos fines específicos y a la proporcionalidad entre la decisión de la Administración y los hechos que le dan fundamento a la misma; además, por cuanto la decisión adoptada por la Administración debe encontrar fundamento en motivos suficientes que permitan diferenciar la actuación administrativa discrecional de la arbitraria y del abuso de las facultades otorgada. De manera concordante con lo anteriormente expuesto, esta Corporación ha establecido que en materia de actos administrativos expedidos en ejercicio de facultades discrecionales, dicha discrecionalidad no implica indefectiblemente que la Administración se exonere del deber de motivar sus decisiones. En efecto, la jurisprudencia constitucional ha sido enfática en establecer la importancia de la motivación de los actos administrativos, como garantía de que los destinatarios del mismo puedan conocer las razones en las que se funda la Administración al adoptar decisiones que afecten sus intereses generales o particulares" 
hace nugatoria la posibilidad para el afectado de ejercer su Derecho de Defensa.

Esta posición implica un cambio importante en el ejercicio de la facultad discrecional para desvincular personal Militar de las Fuerzas Militares en Colombia, toda vez que queda sentado con claridad el principio según el cual, las simples "razones del servicio" no son una motivación suficiente del acto de desvinculación de estos funcionarios como aparentemente hasta ahora se había considerado. Así, si bien la administración puede desvincular por "razones del servicio", el afectado debe conocer los motivos en los que se sustenta dicha desvinculación, para que se entienda que el acto ha sido motivado suficientemente y para que, por una parte, se le garantice el ejercicio del derecho de defensa al afectado con la decisión y por otra parte, que la actividad de la administración no sea considerada arbitraria. En efecto, si tenemos en cuenta que por la vía del contencioso administrativo el funcionario solo puede solicitar, en este caso, la nulidad del acto por expedición irregular, pero no - por no ser la vía legal idónea - que se motive adecuadamente el mismo, el desconocimiento de los motivos que sirven de fundamento al acto de desvinculación, pondría al funcionario en la imposibilidad de ejercer su derecho de defensa y por ello la actividad de la administración se convierte en una actuación arbitraria. En este sentido afirma el Consejo de Estado:

"E1 desconocimiento de las razones que sustentan el despido del servicio se considera una actitud arbitraria que amerita la protección constitucional porque las acciones contenciosas no resultan idóneas para obtener que la administración motive su acto permitiendo que el afectado controvierta la legalidad del mismo, única garantía de que pueda acudir al proceso contencioso en ejercicio de la plenitud de sus derechos"
Si analizamos la posición del Consejo de Estado desde el punto de vista del funcionario, es evidente que solo nos remitiríamos a observaciones en términos de garantía del ejercicio del derecho de defensa y a anotaciones sobre el hecho que como juez de tutela este comienza a darle fuerza a ciertas jurisprudencias de los jueces de lo Contencioso Administrativo que intentan aplicar la distinción entre la Carga de la impugnación y la carga de la prueba que tiene todo accionante. Una distinción que, compartiendo la posición de $\mathrm{MARIN}^{14}$, nos parece absolutamente necesaria para garantizar el acceso a la administración de justicia de los funcionarios en general y de los funcionarios militares en particular. Pero si lo analizamos desde el lado contrario de la relación jurídica, es decir desde el punto de vista de la administración, lo que encontramos es la obligación para esta de realizar estudios solidamente elaborados que reflejen el análisis serio de los hechos ${ }^{15}$ que dan fundamento a su decisión de desvincular al funcionario del servicio activo. De lo anterior se colige que la administración no se puede ocultar detrás de lo que se denomina el "Anquilosado Paradigma" de la prevalencia de un interés sobre el otro ${ }^{16}$ - que para este caso consistiría en argumentar que las "razones del servicio" no necesitan mas explicación que el ser una medida de salvaguarda del interés general necesaria dentro de un país en conflicto

14 MARÍN, Hugo. Discrecionalidad Administrativa, Universidad Externado de Colombia, Bogotá, 2007, p.774.

15 En este punto es importante precisar como lo ha hecho de manera reiterada la Corte constitucional y el Consejo de Estado que la facultad discrecional no es una sanción, de lo que se colige que no se trata para la administración de realizar un proceso completo en el cual el funcionario vaya a ser juzgado, se trata simplemente de que estas actas reflejen los motivos objetivos y razonables que llevan a las juntas o comités a recomendar el retiro del funcionario.

16 GONZÁLES NAVARRO, Francisco, citado por GORDILLO, Agustín, Tratado de derecho Administrativo, Biblioteca jurídica Diké y Fundación de Derecho Administrativo. Medellín, 1999. $1^{\text {a }}$ Ed. Colombiana. p.39. 
- pues esto constituiría, en los términos de GORDILLO $^{17}$, una falacia no formal que lleva a que el acto este ilógicamente motivado y que por ende deba ser declarado nulo.

Al confirmar que la administración debe consignar claramente, en las Actas de la junta Asesora del Ministerio de Defensa, los motivos en los que se fundamenta la utilización de la facultad discrecional para desvincular a un funcionario militar de las Fuerzas Militares, con el fin de que este pueda ejercer su derecho a la defensa, se debe entender de una vez por todas que la inadecuada elaboración de las actas de las reuniones de los comités o juntas en los que se decide recomendar o no el retiro de un funcionario y que sirven de causa al acto de desvinculación o que las mismas contengan expresiones vagas y vacuas como por ejemplo "por ser conveniente a los superiores intereses del Estado" o "en virtud de las atribuciones que le confiere la ley" equivalen, en sentido material más no formal, a la inexistencia de fundamentación pues significan "inutilizar totalmente la defensa o argumentación"18. De lo que se colige que si bien el acto administrativo no necesita expresar la motivación, los documentos que reflejan las reuniones de los comités o juntas que deben recomendar o no el retiro de un funcionario, deben consignar claramente el análisis y expresar de manera exhaustiva cuales son los elementos que le llevan a recomendar o no el retiro de un funcionario, pues una actuación contraria a la que se propone, equivaldría a hacer, se insiste, absolutamente imposible el ejercicio del derecho de defensa del funcionario, pues este desconocería los motivos en que su fundamenta la decisión de desvinculación. Así, en los términos de nuevo de GORDILLO ${ }^{19}$, la administración está obligada a explicar exhaustivamente cuales son

\begin{tabular}{ll}
\hline 17 & Ibidem. p. 40. \\
18 & Ibidem. \\
19 & Ibidem.
\end{tabular}

los hechos que se consideran probados, qué valoración reciben, qué relación existe entre tales hechos, etc. En este orden, la motivación suficiente no es una cuestión de forma como de manera evidente se ha venido asumiendo por parte de la Administración colombiana en esta materia, sino que es un elemento de fondo pues hace referencia directa al contenido del acto y a la razonabilidad de la decisión ${ }^{20}$. Utilizando los términos de MARIN, aún frente a supuestos como el del ejercicio de la facultad discrecional, la administración "no puede olvidarse de la perentoriedad de instruir un procedimiento administrativo que le garantice cumplir con las exigencias derivadas del principio de objetividad y el deber de administración, incorporar unos - todos los - hechos que objetiva y verazmente fundamenten su elección, $y$ ponderar adecuadamente todos los bienes, valores $y$ derechos implicados, de suerte que se cumpla la garantía prevista en el igualmente multicitado art 36 CCA, en el sentido que la resolución dictada en ejercicio de facultades discrecionales sea proporcional a los hechos que le sirven de fundamento" ${ }^{21}$.

$20 \quad$ En este sentido y con respecto a la diferencia entre la exigencia de motivación y la justificación de los motivos, el Consejo de Estado manifestó en sentencia del 8 de mayo de 2003, M.P. Alejandro Ordóñez Maldonado, Referencia: 3274-02 Actor: José Humberto Medina Donato, que: "(...) el poder discrecional no es un atributo omnimodo que le permita a las autoridades actuar soberanamente, puesto que no obstante que emana del privilegio que ostenta la administración de hacer efectivos los principios de ejecutoriedad y ejecutividad de sus decisiones, la autoridad debe tener presente que los poderes estatales no son un fin en si mismo sino un medio al servicio de la sociedad y que sus decisiones surgen de la ordenación de unos hechos para lograr llegar a una finalidad.(...)

Cabe destacar, que el artículo 36 del C.C.A., consagra la regla general de la discrecionalidad y señala la proporcionalidad entre los hechos que le sirven de causa, que no es otra cosa que la acción del hecho causal sobre el efecto jurídico, la medida o razón que objetivamente debe existir entre la realidad de hecho y el derecho que supone la verdad de los hechos y su conexidad con la decisión"

21 MARIN, Hugo. Discrecionalidad Administrativa, op. cit., p.780. 
En este sentido es también fundamental subrayar que con esta imposición de comunicar el contenido de las actas - la causa del acto de desvinculación - se dejan claras dos cosas que ya están perfectamente desarrolladas en el campo teórico pero no así en el práctico. En primer lugar, que el funcionario que puede ser retirado con fundamento en la facultad discrecional no se convierte por ese simple hecho en un funcionario de libre nombramiento y remoción, este funcionario sigue siendo de carrera (vocación de estabilidad) y lo que sucede es que de manera excepcional, se le permite a la administración truncar dicha carrera para que se logren concretar los fines del Estado. En segundo lugar, que una cosa es el acto político o de gobierno y otra muy diferente el acto administrativo que se expide en ejercicio de la facultad discrecional. En efecto, mientras en el primero los motivos y la motivación son estrictamente políticos y por ello no necesitan fundamentarse en razones objetivas, en el caso de los actos de desvinculación de funcionarios expedidos en ejercicio de la facultad discrecional, las razones deben ser objetivas, luego al evaluar este acto, si bien no se analiza la conveniencia o inconveniencia de la decisión, sí se analiza la existencia de los motivos, la proporcionalidad de estos con dicha decisión ${ }^{22}$. Con base en lo anterior es claro que, dentro del ejercicio de la facultad discrecional,

22 Con respecto a la diferenciación entre los actos políticos y los actos expedidos en ejercicio de facultad discrecional, compartimos la posición de BERROCAL cuando a manera de ejemplo manifiesta que "una es la discrecionalidad de un alcalde en relación con los cargos de representación politica, en los cuales puede determinar la oportunidad, el mérito, la conveniencia y los motivos" y otra, "la discrecionalidad en relación con cargos no políticos y que no estén sujetos a carrera, en los que apenas puede determinar la oportunidad y la conveniencia, ya que los motivos están limitados por las necesidades del servicio, lo cual excluye motivos que si son admisibles en los actos respecto de cargos de representación politica, como pueden ser motivos politicos partidistas o puramente personales ajenos a las necesidades del servicio." BERROCAL, Luis Enrique, Manual del acto Administrativo, Ediciones Librería del Profesional. Bogotá, 2009, 5ª Ed. p.177. la causa del acto, por una parte, debe ser conocida por los funcionarios para que estos puedan ejercer su derecho de defensa y por otra parte, los jueces colombianos tienen la competencia para evaluar los hechos que constituyen la causa del Acto Discrecional, sin que por ello se deba considerar afectada la facultad de la administración para pronunciarse sobre la oportunidad o conveniencia de la decisión. Con respecto a este último punto, es importante precisar que la competencia de los jueces administrativos para pronunciarse sobre la causa del Acto de retiro por Facultad discrecional, de acuerdo con la posición adoptada en la materia por los mismos jueces en las sentencias mencionadas anteriormente, no es más que la obligación que tiene todo juez de verificar la existencia y validez de todo elemento ad substantiam actum del acto definitivo, como lo son en este caso, las Actas de evaluación de la junta asesora del Ministerio de Defensa para el Acto Administrativo de Retiro $^{23}$, con el fin de establecer la legalidad del Acto que se le ha sometido a evaluación.

Con la exigencia de la motivación suficiente de los actos administrativos de desvinculación de los funcionarios militares de las Fuerzas Militares, concretada en la exigencia de la publicación y adecuada elaboración de las Actas de

23 En esta misma vía interpretativa que opera en Colombia - ver por ejemplo, Consejo de Estado, Sala de lo contencioso administrativo, Sección Segunda, Subsección B, sentencia del 18 de mayo de 2000, M.P. Alejandro Ordóñez Maldonado, Referencia: 2459-99 Actor: Doris Isabel Ceballos Mendoza, Demandado: Instituto de Seguros Sociales - se ubica, al igual que la jurisprudencia francesa, una parte de la jurisprudencia argentina en lo Federal, la cual manifiesta de manera expresa que "La exactitud material de los hechos que motivan la decisión administrativa constituye una condición general de legalidad de todo acto administrativo, por lo que, como se ha dicho, los jueces están facultados para verificar la materialidad de las faltas que motivan las medidas discrecionales". Fallo "Marra de Melincoff, Alicia Leonor c/Universidad de Buenos Aires", citado por CASSAGNE, Juan C, El principio de la legalidad y el control judicial de la discrecionalidad administrativa, Marcial Pons, Buenos Aires, 2009 , p.208. 
recomendación, lo que se busca es que el sujeto que es retirado, al interponer su demanda, pueda someter ante el juez el análisis de la existencia de los motivos y controvertir tanto dicha existencia, como la razonabilidad del acto ${ }^{24}$. Sin embargo, la exigencia de motivación suficiente no solo permite a los funcionarios afectados ejercer su derecho de defensa sino, en mi concepto, a la colectividad de ejercer su derecho a fiscalizar la actividad de la administración en lo que al aprovechamiento de sus recursos se refiere y por esta vía, de la mano de la actividad jurisdiccional, contribuir también a una mejor administración de los recursos humanos dentro de las Fuerzas Militares y una gestión eficiente de la Administración en su conjunto.

\section{LA EXIGENCIA JURISDICCIONAL DE MOTIVACIÓN SUFICIENTE, UNA GARANTÍA DE PLANEACIÓN Y GESTIÓN EFICIENTE DE LOS RECURSOS HUMANOS}

La actuación eficiente del Estado no es más un simple objetivo deseado sino una obligación que en el caso colombiano se encuentra consagrada en su Constitución Política como principio de la Actuación administrativa. Esta actuación eficiente, no puede sin embargo concretarse en el campo del ejercicio de la Facultad discrecional para la desvinculación de personal militar de las Fuerzas Militares, si dicho ejercicio no se

$24 \quad$ En este punto hacemos referencia al control de la razonabilidad del acto de retiro, en términos de control de la oportunidad o conveniencia de la decisión y su proporcionalidad en relación con los hechos que le dan origen. Así entonces, diferenciamos esta razonabilidad, de la razonabilidad económica que utilizamos para efectos de determinar la existencia de una gestión eficiente de la Administración en materia de Derechos Humanos. La posibilidad y obligación para los jueces de realizar un control de la oportunidad de la Decisión discrecional en función de la proporcionalidad de la misma con la causa que le da origen, fue plasmada por el Consejo de Estado en sentencia del 8 de mayo de 2003, M.P. Alejandro Ordóñez Maldonado, Referencia: 3274-02 Actor: José Humberto Medina Donato. realiza dentro de los límites de la racionalidad económica y jurídica que debe determinar la utilización de los recursos disponibles y en particular la utilización del recurso humano.

Si tenemos en cuenta que la racionalidad económica - entendida como la conducta optimizadora en la que los consumidores maximizan la utilidad y las empresas maximizan los beneficios $^{25}$ - y la racionalidad jurídica - entendida, con respecto a la Administración pública, como la actividad determinada por la voluntad de maximizar los beneficios de la colectividad son elementos esenciales para alcanzar el mejor aprovechamiento de los recursos disponibles, su desconocimiento conlleva directamente a la ineficiencia en la actuación de la Administración. En otros términos, toda actuación irracional (económica o jurídicamente considerada) conlleva a una actuación ineficiente de la Administración y por ende, en el caso colombiano, a un desconocimiento de por 10 menos, uno de los principios constitucionales determinadores de la actividad administrativa.

La clásica discusión consistente en evaluar la discrecionalidad desde la perspectiva de la separación de los poderes es insuficiente para encuadrar el planteamiento anterior, por ello, el punto de vista de la eficiencia y la racionalidad que le subyace, y que se plantea para el análisis del ejercicio de la discrecionalidad - aplicado al caso concreto de la Facultad Discrecional para desvincular miembros militares de las Fuerzas Militares colombianas - corresponde a una perspectiva ampliada en la que se entiende que los límites que se le imponen al ejercicio de esta facultad discrecional por parte de los jueces, no son simples mecanismos encaminados a evitar la arbitrariedad, sino que se convierten en instrumentos que contribuyen a garantizar el desarrollo de una actividad pública eficiente, de

25 SAMUELSON/NORDHAUS, Economía, Decimosexta Edición. McGraw-Hill. p., 183. 
lo que se infiere que "juzgar a la administración, contribuye también a administrar mejor" 2627.

En el caso particular del cual nos ocupamos, la contribución a la eficiencia se deriva de la imposición que hacen los jueces administrativos y constitucionales a la administración, consistente en establecerle límites al ejercicio de la facultad discrecional, obligándola a motivar de manera suficiente los actos administrativos de desvinculación de los funcionarios militares a través de la publicación de las actas en las que se manifiestan las razones que sirven de base a la recomendación del despido y que constituyen la causa del acto discrecional de retiro. Sin embargo, dicha contribución materializa su presión por la eficiencia a través de dos vías diferentes. Una primera vía, que podríamos denominar como directa, de acuerdo con la cual, la imposición que se expresa a través de los límites impuestos al ejercicio de la Facultad discrecional, trae como consecuencia una presión para que el Estado realice una planeación más eficiente de sus recursos humanos, so pena de verse sancionada y condenada al pago de indemnizaciones de perjuicios como consecuencia de desvincular a sus funcionarios, por la vía de la facultad discrecional, fundamentado en argumentos carentes de objetividad. En este orden - teniendo en cuenta que la motivación del Acto sólo puede ser racional si se encuentra en adecuación con una causa o motivo objetivo - dentro del marco de esta primera vía la lógica consiste en afirmar que los límites impuestos por la jurisdicción, generan una correlativa presión sobre la administración para que enmarque toda desvinculación dentro

26 FERNÁNDEZ, Tomás-Ramón, Discrecionalidad Arbitrariedad y Control Jurisdiccional, Palestra Editores, 2006, p. 358.

27 Con fundamento en la misma lógica se puede analizar el ejercicio de esta facultad discrecional desde la perspectiva de otros principios constitucionales, sin embargo, dicho análisis desborda el objeto del presente artículo, razón por la cual, tal análisis será objeto de futuros trabajos de reflexión sobre este tema. de políticas estructuradas y claras de recursos humanos. Lo anterior por cuanto resultaría irracional tanto desde el punto de vista económico como jurídico y por ende contrario al principio de eficiencia que, fundamentado en una apreciación puramente subjetiva y desprendida de una política clara de utilización de los recursos humanos, decidiera prescindir de los servicios de un funcionario en cuya preparación ha invertido importantes recursos públicos, los cuales está en la obligación de utilizar de manera eficiente.

En efecto, si se tiene en cuenta que los limites impuestos por los jueces al ejercicio de la Facultad discrecional para desvincular funcionarios militares, implican que la administración no puede escudarse detrás de lo que denominábamos en los términos de GORDILLO el "Anquilosado Paradigma" de la prevalencia de un interés sobre el otro, pues ello constituye una falacia no formal ${ }^{28}$, la administración está obligada a fundamentar su actuación en motivos objetivos que permitan dilucidar que si bien la conveniencia de la actuación corresponde, en aras del mantenimiento de la discrecionalidad, de manera exclusiva a la administración, dicha conveniencia debe poder justificarse en presupuestos objetivos cuya validez solo puede ser constatada en la medida que los mismos se encuentren enmarcados dentro de una política seria de recursos humanos. Considero que solo en el marco de una política de planeación de recursos humanos es realmente posible probar la racionalidad tanto económica como jurídica de la decisión en términos de eficiencia y por ende, comprobar que está encaminada a la búsqueda de la realización de los fines del Estado. Una realización que sólo puede ser alcanzada si su comportamiento obedece a los principios de racionalidad.

De manera concreta, podríamos decir que en la medida que la desvinculación de un funcionario

$28 \quad$ Ver supra., p.1. 
no se encuentre fundamentada en motivos objetivos que se enmarquen en políticas claras de manejo y gestión de recursos humanos, dicha desvinculación es ilegal y contraria al principio de eficiencia por cuanto debe ser considerada como una acción irracional de la administración. Una irracionalidad derivada del hecho que si la causa del acto no es objetiva y no puede ser evaluada a la luz de una política clara de planeación y manejo de recursos humanos, la decisión de conveniencia (la desvinculación) no podría ser considerada como encaminada a maximizar los beneficios de la administración individualmente considerada - racionalidad económica - y de la colectividad - racionalidad jurídica -. A contrario, si los motivos en que se fundamenta el acto de desvinculación son objetivos, como lo exigen los límites impuestos por los jueces y se encuentran enmarcados dentro de políticas estructuradas de Recursos Humanos, entonces la actividad podrá ser considerada como racional en términos económicos y jurídicos. En este orden, los límites impuestos por los jueces, impiden a la administración el estar dando bandazos, escudados en la supuesta garantía del orden público, en materia de manejo de recursos humanos, obligándola a tomar decisiones con base en políticas objetivas y claras de planeación y manejo de estos recursos.

Manifestábamos, sin embargo, que existe una segunda vía a través de la cual se materializa la presión por la eficiencia derivada de las imposiciones que hacen los jueces a la administración y que implican unos límites al ejercicio de la Facultad discrecional. Esta segunda vía, que podemos denominar indirecta, consiste en una apertura para que los ciudadanos puedan exigir, a través de los mecanismos de fiscalización que les otorga el ordenamiento jurídico colombiano $^{29}$, una adecuada planeación de los recursos humanos al interior de las Fuerzas Militares. Esta apertura surge de la posibilidad

$29 \quad$ Por ejemplo las Acciones Populares. que se genera para los ciudadanos de exigir a dicha administración, fundamentados en los límites impuestos por parte de los jueces al ejercicio de la facultad discrecional, a través de la exigencia de motivación suficiente de los actos de desvinculación, explicaciones relacionadas con la manera en como son utilizados los dineros públicos en el manejo de los recursos humanos al interior de las Fuerzas Militares. En otros términos, es una apertura que surge de la posibilidad que se le abre a los ciudadanos de, a partir del conocimiento de elementos objetivos, evaluar la actividad del Estado en términos de eficiencia y de la obligación que tiene la Administración de demostrar que su actividad es racional tanto desde el punto de vista económico como jurídico.

En efecto, si tenemos en cuenta que por una parte, Colombia es un país que afronta un conflicto interno que obliga a que el gasto militar represente el $5.6 \%$ del $\mathrm{PIB}^{30}$ y que por otra parte, dentro de dicho gasto el componente de la preparación del personal ocupa más del 30\% del mismo, resulta por lo menos comprensible y explicable que la Administración deba demostrar objetivamente - insistimos, sin escudarse en el anquilosado paradigma de la prevalencia de un interés sobre el otro - que las decisiones de desvinculación de oficiales, suboficiales o soldados con fundamento en la facultad discrecional obedece al principio de eficiencia. En términos un poco más sencillos, dada la importancia del gasto militar en un país como Colombia y del gasto en la preparación de sus Militares, la administración debe estar en la capacidad de explicar de manera objetiva, ante la fiscalización de los ciudadanos, por qué oficiales o suboficiales en cuya formación nuestras Fuerzas Militares invierten una gran cantidad de dinero, son de un día para otro desvinculados de la institución, sin más explicación que

30 Gasto Militar para el 2008 en Colombia de acuerdo con las cifras del Departamento Nacional de Planeación. 
"las razones del servicio". Es decir, demostrar que la "pérdida" de los dineros invertidos en la preparación de sus recursos humanos, obedece a una actuación racional y no a un impulso meramente subjetivo ${ }^{31}$.

En estos términos, de la fiscalización por parte de los ciudadanos y de la obligación que consideramos en un Estado Social de Derecho como el colombiano tiene la Administración de demostrar que sus actuaciones deben estar dirigidas hacia la realización de una actividad eficiente; considero que se deriva para la Administración, una correlativa presión para que implemente una clara y transparente política de Planeación de Recursos Humanos dentro de la cual pueda enmarcar sus decisiones de desvinculación por facultad discrecional.

Sin embargo, el impacto que en materia de planeación eficiente de recursos humanos tienen los limites impuestos por los jueces al ejercicio de la facultad discrecional para desvincular funcionarios militares deriva su mayor interés, del hecho que de la obligación de motivación suficiente de los actos de desvinculación por facultad discrecional, se deriva de manera extensiva para las Fuerzas Militares colombianas, la obligación de motivar suficientemente todo acto que implique desvinculación de un miembro militar de la fuerza, como lo sería, por ejemplo, la no recomendación de ascenso de un oficial o suboficial al grado inmediatamente superior $^{32}$.

31 En este sentido, me permito precisar que si bien estoy convencido que la relación de confianza es elemento fundamental dentro de las instituciones militares, a su vez estoy convencido que la ruptura de esa relación como fundamento de una decisión de desvinculación debe fundamentarse en causas objetivas, pues en tratándose del rubro más importante en materia de gasto público, lo mínimo que se puede esperar es que la ejecución de dicho presupuesto se realice siguiendo lógicas racionales que permitan desarrollar una actividad eficiente.

32 En este sentido hay que afirmar que si bien la estructura castrense es piramidal, la institución debe estar en
En este orden, si la aplicación de los límites al ejercicio de la facultad discrecional es asumida como una obligación general que debe ser aplicada extensivamente a todo acto de desvinculación, esto redundaría en un mejoramiento en la planeación de Recursos Humanos al interior de las Fuerzas Militares colombianas, dado que la administración estaría obligada en todo momento a demostrar, que sus decisiones discrecionales en materia de desvinculación se encuentran fundamentadas en causas objetivas y no en elementos puramente subjetivos. Es decir, demostrar que la manera como manejan los recursos públicos destinados a la preparación y mantenimiento del recurso humano dentro de la Fuerza, se encuentra enmarcada dentro de una política clara de planeación de recursos humanos cuyo objetivo principal es el de la materialización del principio de eficiencia y de la racionalidad que le es subyacente, como presupuestos esenciales para alcanzar el beneficio de la colectividad y de la administración pública individualmente considerada. En ocasiones resulta inexplicable encontrar que por el camino son dejados de lado miembros militares en cuya formación la Fuerza ha invertido una cantidad muy importante de recursos públicos, sin más explicación o fundamento que la existencia de una estructura piramidal o las razones

capacidad de demostrar de manera objetiva que quien se encuentre en la cúspide es el mejor de entre aquellos que podían acceder a dicho cargo. Se hace referencia a la situación particular de los ascensos porque, en esta materia, como consecuencia de decisiones discrecionales fundamentadas en Actas mal elaboradas o simplemente ilegales por vicios del consentimiento y por lo mismo, de manera evidente no enmarcadas en políticas eficientes de gestión de recursos humanos, el Estado se ha visto, como en el caso de retiro por "razones del servicio", condenado por que sus actos se encontraban viciados por falsa motivación y también por desviación de poder. Tribunal Administrativo de Cundinamarca, sentencia del 18 de febrero de 2002, Referencia: 993520; Tribunal Administrativo de Cundinamarca, sentencia del 10 de Octubre de 2009, Referencia: 200566704 Actor: José Humberto Medina Donato.Tribunal Administrativo de Cundinamarca, Sección segunda, sentencia de 2003, Ref:993520. 
del servicio, lo que choca directamente con los principios de la eficiencia y ha llevado a que el Estado sea condenado.

\section{CONCLUSIÓN}

A manera de conclusión, se puede entonces afirmar que - derivado de la fiscalización y de la obligación de la administración de motivar de manera suficiente sus decisiones de desvincular funcionarios militares con fundamento en el ejercicio de la facultad discrecional que le otorga la ley - los límites impuestos por el juez al ejercicio de esta facultad al interior de las Fuerzas Militares contribuyen a administrar mejor, pues generan la obligación para el Estado de enmarcar sus decisiones dentro de políticas estructuradas de planeación de Recursos Humanos al interior de la institución militar, que redundan en un mejoramiento de la eficiencia en el actuar de la administración y en un mayor respeto y garantía de los derechos fundamentales de los miembros de las Fuerzas Militares. Sin embargo, la denominada facultad discrecional para retirar funcionarios no se encuentra limitada al campo de las Fuerzas Militares, sino que existen otras normas que autorizan el ejercicio de dicha facultad en la Policía Nacional ${ }^{33}$, en el Departamento Administrativo de Seguridad (DAS) ${ }^{34}$ y en el Instituto Nacional Penitenciario (INPEC) ${ }^{35}$, instituciones estas que por su carácter civil ameritan un análisis especial y diferenciado que permita aclarar si el ejercicio de esta facultad es un mecanismo que genera eficiencia en el actuar de la Administración Pública en su conjunto y si los límites impuestos al ejercicio de la misma

\footnotetext{
$33 \quad$ Ley 857 de 2003.

$34 \quad$ Decreto 2147 de 1989.

35 Decreto-Ley 407 de 1994.
}

por los jueces, contribuye, como en el caso de las Fuerzas Militares, a administrar mejor.

\section{BIBLIOGRAFÍA}

ABATE, Bernard, La Nouvelle Gestion Publique, LGDJ, Paris, 2000.

AUBY, Jean-Bernard, La globalisation, le droit et l'Etat, Montchrestien, Paris, 2003.

BERROCAL, Luis Enrique, Manual del acto Administrativo, Ediciones Librería del Profesional. Bogotá, 2001.

CASSAGNE, Juan C, El principio de la legalidad y el control judicial de la discrecionalidad administrativa, Marcial Pons, Buenos Aires, 2009.

FERNÁNDEZ, Tomás-Ramón, Discrecionalidad Arbitrariedad y Control Jurisdiccional, Palestra Editores, Lima, 2006.

GORDILLO, Agustín, Tratado de derecho Administrativo, Biblioteca jurídica Diké y Fundación de Derecho Administrativo. Medellín, 1999.

JAMES, Harold, From Grandmotherliness to gouvernance. The evolution of IMF conditionality, The evolution of IMF conditionality, Finance and Developpement Review, Vol 35, N4, 1998.

NORTH, Douglass, Instituciones Cambio Institucional y desempeño económico, Fondo de cultura Económica, México, 2000.

MARÍN, Hugo A, Discrecionalidad Administrativa, Universidad Externado de Colombia, Bogotá, 2007.

ROEMER, Andrés, Introducción al análisis económico del derecho, ITAM, México, 1994.

RUBIO, Mauricio, Economía Jurídica. Introducción al análisis económico del derecho Latinoamericano, Universidad Externado de Colombia, Bogotá, 2007.

SAMUELSON / NORDHAUS, Economia, Décimo sexta edición, McGraw-Hill, 